\title{
The Predictive Value of Job Satisfaction and Relevant Factors in Predicting of Commitment in the Workplace, Job Involvement and Job Opportunity of Bank Employees
}

\section{Qufli Osmani}

\author{
Fama College, R. of Kosovo and State University of Tetovo, R. of Macedonia
}

Kushtrim Gashi

Fama College, R. of Kosovo

\author{
Doi:10.5901/ajis.2015.v4n2s1p168
}

\begin{abstract}
Human resource management involves multiple areas of integration of management and employees. But the most important segment of quality and comprehensive report remains reliable employee who is satisfied by the work, willing to progress and learn. The last decades with complete certainty, it can be stated that job satisfaction and similar phenomena appears in the role of the most important explanatory constructions, as in the field of empirical research, psychometric measurement, as well as in the applicative. The purpose of this research corresponds with intent to verify the predictive value of job satisfaction (including its structural components), as well as relevant factors in explaining the commitment, involvement and job opportunities for bank employees. Research results claimed linear interaction even the predictive value of tested models. Model which includes job satisfaction and its structural components, together explains $38.9 \%$ of criterion variables $118.8 \%$ of the criterion variable commitment in the workplace, $14.2 \%$ of the criterion variable job opportunities, and $5.9 \%$ of the criterion variable job involvement). On the other hand the relevant factors together explain about $13 \%$ of the variances of criterion variables (13\% for job involvement, $2.4 \%$ for commitment in the workplace and $1 \%$ for the job opportunity). The research was conducted on a sample of 104 subjects (age 25 and 62 years) of all employed in regular employment in the four largest commercial banks in Kosovo.
\end{abstract}

Keywords: the predictive values, job satisfaction, commitment in the workplace, job involvement, job opportunity

\section{Introduction}

Management of human resources in a company, among other things refers to the fulfillment of economic and psychological component of work, in order to create conditions for an efficient and effective company. One of the factors that relate to the effective transformation of the company is employee motivation segment in order to maximize their performance and all this in the function of the greater achievements. In fulfilling the goal of achieving greater competitive power of workers (exposing the different motivational strategies) often out of human resource management diopter is the question of what the workers really want?

Numerous studies and professional experience assert that the professional work we do is of particular importance. Why? Because $1 / 3$ of the day, 1/3 of the week, $1 / 2$ of life we spend at work, which on average we spend 75,600 hours of work ?! If we put in mutual relation work commitment and job satisfaction, then we do not have hard to justify in particular the central role of work and job satisfaction. During the past 100 years, the job satisfaction concept has evolved as both structurally conceptually. Taylor and Gilbreth (1911), according to Wright (2006) they conceptualizing first theoretical principles about satisfaction by placing job satisfaction in the psychological relation. According to the theory of Taylor to have job satisfaction, management principles needed to be accepted as personal principles.

According to Wright (2006) viewed chronologically, the first provisions on job satisfaction refers Hoppock (1935). According to him, the job satisfaction presents a consequence of the interaction of psychological, physiological and physical (environmental) factors. From their interaction will depend on whether individual means "I am satisfied with the work".

Based on scientific literature, that addresses the issue of job satisfaction mainly refers two main lines defining. First, the job satisfaction defines as one-dimensional concept, mostly holistic character according to which satisfaction is defined as feeling which refers to labor in general. According to the second line, satisfaction is determined by a multifaceted prism, respectively that the subject feels to the work can disseminated as the sum of pleasures with specific 
aspects of the work (Herzberg, 1959 according to Greenberg \& Baron, 1998; Spector, 1997). In this line Spector (1997, p. 2), defines the job satisfaction as "just as people feel about their work and different aspects of their work".

Different definitions on hypothetical construct "job satisfaction" refer more semantic differences rather than the origin of the construct. In fact, many scholars share the opinion that in essence construct stays the emotional processes, feelings that have been revoked from work, for example Locke $(1969$, p. 316) the job satisfaction defines as "pleasant emotional state that is caused by the assessment that the work it performs, achieves or assists individual values". Mainly, it dominates the view that professional satisfaction can be defined as cognitive response (what the individual know about his work and residence), affective (how we want or not one thing or person) and evaluative (or behavioral which refers to the provision that to act or not in the specific direction) of the individual against his own work (by Grinberg \& Baron, 1998). The theoretical framework of this research in empirical form refers to the theory of Paul Spector (1997) which defines job satisfaction as a additive concept, respectively as the sum of feelings (pleasure partial) associated with various aspects of work.

Commitment in the workplace - Meyer and Allen (1993) have created three-component model of professional commitment. Three component model is linked with different psychological forms. During the conceptualization of the model in question, Meyer and Allen as the starting point had the need of researchers in the field of work commitment as a reference point in the interpretation of empirical research and at the same time to serve as a pragmatic framework for new researches. Their study was based mainly on previous studies on work of commitment. Meyer and Allen factorial analysis enabled the extraction of three structural components of professional commitment, including:

1. Emotional commitment which refers to the acceptance of the aims of the organization and the individual great confidence in those purposes. Emotional commitment is mainly attributed to positive emotional polarity and desire for work commitment that is influenced by several different demographic characteristics: age, residence, gender and education;

2. Continued commitment refers willingness to make considerable efforts for the organization;

3. Normative commitment refers to the existence of a certain desire to maintain organizational membership. The obligation for employee becomes impeller, to engage and to repay a "moral debt". For example, the organization may have invested resources in the training of an employee who then feels as "moral obligation" to put forth efforts to work and stay with the organization to repay debt.

Commitment in the workplace conceptually treated as a concept broader and more comprehensive than job satisfaction. It includes workers' willingness to sacrifice for their organization and to himself attributes to emphasize emotional commitment than to professional satisfaction.

Job involvement. There are many definitions of professional involvement. Job involvement is defined as the degree to which a person is motivated for a job (Bashaw \& Grant, 1994).

Job opportunity - described as rating scale workers' demands to work or as the balance of workers with resources and labor requirements (IImarinen J., et al. In 2004 by Martin Hasselhorn H. 2008).

In the research included a series of socio-demographic characteristics whose effect is treated as important for the treatment of theoretical and empirical research results. Socio-demographic characteristics are considered as individually and each employee brings to their work environment. Some of the characteristics comprise demographic identity (gender, calendar age, ethnicity, religion, etc.), others "background" personal (education level, etc.), social personal status (marital status, number of children, economic status), psychosocial support (climate at work, relations with colleagues). Personal attributes affect how it will be perceived and evaluated professional satisfaction (Meyer and Allen, 1993; Herzberg, 1957, 1968). Various empirical results claim that between attributes such as education, gender, ethnicity, calendar age and job satisfaction does not exist a significant correlation (Carlson at al., 2003; Holmes Norton, 2003; Lambert at al., 2007). Also, between marital status and job satisfaction does not exist a significant correlation (Holmes Norton, 2003; Lambert at al., 2007).

\section{Research Methods}

The problem of this research can be conceptualized through the question whether and to what extent the professional satisfaction and its structural components, on the one hand and relevant factors, on the other hand appear in the role predictor of professional commitment, job involvement and the job opportunity.

The aim of the research is to determine the predictive value of professional satisfaction and relevant factors in predicting of professional commitment, job involvement and the job opportunity.

Taking as its starting point the research question and hypothesis can determine: a) important variables research, 
professional satisfaction and its structural components appear in the role of high-value predictive variables, for criterion professional commitment, job involvement and job opportunity variable, and b) based on relevant predictors: kind of rewards, the number of rewards, promotion, job duration, the amount of salary, position at work, the duration on current position and the number of promotions, successfully can predict differences individual of bank employees in the context of professional commitment, job involvement and the job opportunity.

\subsection{Sample}

The sample that represents the population of the bank employees was intentional sample type. The sample consisted of employees from seven sub branches of commercial banks that conduct their activities in the region of Prizren. The sample consisted of a total of 104 bank employees ( 75 male and 35 female) from all levels of the banking hierarchy.

In order to avoid a number of relevant variables which seriously threatened the external validity of research as burnout etc., the research was conducted within the period from August to September 2014. Giving questionnaires was conducted as a group, with the participation of a great number of subjects at the same time.

\subsection{Instruments used}

Professional satisfaction for measuring is applied scale for professional satisfaction assessment (Job Satisfaction Survey) Paul Spector (Spector, 1985). The scale consists of 36 items from which measure 9 structural components of professional satisfaction, Pay, Promotion, Supervision, Fringe Benefits, Contingent rewards, Operating conditions, Coworkers, Nature of work, Communication. Internal consistency with Cronbach alpha scale $a=0.92$ suggests that it is an instrument with high reliability.

For assessment of professional commitment was used three-component model of work commitment instrument (Commitment in the Workplace) by John P. Meyer and Natalie J. Allen. The instrument consists of 20 items from the Likert type. Cronbach alpha reliability $a=0.99$ categories instrument with the highest reliability.

For assessment of job involvement the assessing scale of job involvement was used from Lodahl and Keyner. The instrument consists of 10 items from the Likert type. Internal consistency of the scale expressed through Cronbach's alpha coefficient $\alpha=0.89$.

For assessment of job opportunity was used Job Opportunities instrument with 37 items from the scale which are Likert type. Cronbach alpha reliability $a=0.97$ categorizes instrument with the highest reliability.

For hypothesis testing is applied statistical package SPSS 21, respectively was used parametric and nonparametric statistics, correlation analysis and multiple regression prediction.

\section{Results}

In order to verify the predictive value of researching variables has been used statistical procedure of multiple analysis of regression. Regression analysis was realized on the total sample, including all predictive continual variables.

To determine whether the information provided by the model in which are involved predictors: income, supervision and working procedure are valid or not, it is conducted the analysis of variances. The value of the gained coefficient $F=$ $9.30 p<0.00$ indicates that between the part of explained and unexplained overall variance of the multiple regression exists statistically significant difference. In other words, the information provided by the determinant coefficient is valid.

Determining the relative value of the contribution of specific characteristics in predicting the professional commitment of the employees in the bank is realized through step-wise procedure. Determination of the predictive value was realized through successive inclusion of special predictor in the regressive analysis (Table 1) 


Table1. Table presentation of statistics through which is verified the contribution of
predictor structural components of a job satisfaction in the context of
commitment in the workplace (step-wise analysis)
\begin{tabular}{|l|l|l|c|c|c|c|c|}
\hline \multicolumn{1}{|c|}{ predictor } & $R^{2}$ parcial & $B$ & $p$ & $T$ & P \\
\hline \multicolumn{7}{|c|}{ The model of the variable criteria: Commitment in the workplace } \\
\hline \multirow{5}{*}{$R^{2}=0.300 p<.001$} & $R^{2}=0.242 ; p<.001$ & 0.492 & 0.00 & 5.70 & 0.00 \\
& Income & $R^{2}=0,029 ; p>.001$ & 0.172 & 0.08 & 1.76 & 0.08 \\
& Upgrading & $R^{2}=0.121 ; p<.001$ & 0.347 & 0.00 & 3.74 & 0.00 \\
& Supervision & $R^{2}=0.054 ; p<.001$ & 0.232 & 0.02 & 2.41 & 0.02 \\
& Benefits & $R^{2}=0.082 ; p<.001$ & 0.286 & 0.00 & 3.02 & 0.00 \\
& Rewards & Working Procedures & $R^{2}=0.101 ; p<.001$ & 0.318 & 0.00 & 3.39 & 0.00 \\
& associates & $R^{2}=0.081 ; p<.001$ & 0.284 & 0.00 & 2.99 & 0.00 \\
& Nature of Work & $R^{2}=0.089 ; p<.001$ & 0.299 & 0.00 & 3.16 & 0.00 \\
& Communication & $R^{2}=0.081 ; p<.001$ & 0.285 & 0.00 & 3.00 & 0.00 \\
\hline The model of the variable criteria: Commitment in the workplace \\
\hline \multirow{2}{*}{$R^{2}=0.273 p<.001$} & $R^{2}=0.242 ; p<.001$ & 0.492 & 0.00 & 5.70 & 0.00 \\
\hline & Income & Supervision & $R^{2}=0.121 ; p<.001$ & 0.347 & 0.00 & 3.74 & 0.00 \\
\cline { 2 - 7 } & Working Procedures & $R^{2}=0.101 ; p<.001$ & 0.318 & 0.00 & 3.39 & 0.00 \\
\hline
\end{tabular}

The results presented in Table 1 confirm that the model in which are included structural components of the job satisfaction explains the $30 \%$ of the variance of criterion variables commitment in the workplace. Determinant coefficient value for subcomponent "advancement" suggests that the same should be removed from the model predictive variables, because the value gained is statistically insignificant. The question is, by reducing the number of predictors in model whose involvement can be reached the acceptable predictor? Through successive inclusion of predictive variables in the model, increases the value of regressive coefficients. But the biggest contribution is ensured with the inclusion of subcomponents "income" (14.2\%), followed by sub-component "supervision" (7.1\%) and sub-component "working procedures" (6\%), which all together explain the $27.3 \%$ of commitment in the workplace.

In Table 1, are provided the partial regressive standardized coefficients (beta column). From the height of Partial coefficients we can conclude that statistically significant contribution in predicting the criterion variables at work commitment which ensure the predictors: a) significant satisfaction which derives from income $(B=0.49 ; p<0.01), b)$ satisfaction emphasized which derives from supervision $(B=0.35 ; p<0.01)$ and $c$ ) satisfaction which derives from working procedures $(B=0.32 ; p<0.01$ ). In the context of other predictors (benefits, rewards, associates, nature of work and communication), also concerning their partial contribution is statistically significant, nevertheless the same will not be included in the predictive model because of small contribution they give to prediction for the criterion variables.

Table 2. Tabular presentation of the correlations between significant variables in the research: sub-components of job satisfaction, commitment at work job involvement and job opportunity

\begin{tabular}{|l|l|l|l|l|l|l|l|l|l|}
\hline & Income & Upgrading & $\begin{array}{l}\text { Supervisio } \\
n\end{array}$ & Benefits & Rewards & $\begin{array}{l}\text { Working } \\
\text { Procedure } \\
5\end{array}$ & Associates & $\begin{array}{l}\text { Nature of } \\
\text { Work }\end{array}$ & $\begin{array}{l}\text { communic } \\
\text { ation }\end{array}$ \\
\hline $\begin{array}{l}\text { Commitment } \\
\text { in the } \\
\text { workplace }\end{array}$ & $\begin{array}{l}0.429^{* *} \\
p<0.00\end{array}$ & $\begin{array}{l}0.172 \\
p>0.81\end{array}$ & $\begin{array}{l}0.347^{* *} \\
p<0.00\end{array}$ & $\begin{array}{l}0.232^{*} \\
p<0.02\end{array}$ & $\begin{array}{l}0.286^{* *} \\
p<0.00\end{array}$ & $\begin{array}{l}0.318^{* *} \\
p<0.00\end{array}$ & $\begin{array}{l}0.284^{* *} \\
p<0.00\end{array}$ & $\begin{array}{l}0.299^{* *} \\
p<0.00\end{array}$ & $\begin{array}{l}0.285^{* *} \\
p<0.00\end{array}$ \\
\hline $\begin{array}{l}\text { Job } \\
\text { involvement }\end{array}$ & $\begin{array}{l}0.249^{*} \\
p<0.01\end{array}$ & $\begin{array}{l}0.140 \\
p>0.16\end{array}$ & $\begin{array}{l}0.190 \\
p>0.06\end{array}$ & $\begin{array}{l}0.141 \\
p>0.15\end{array}$ & $\begin{array}{l}0.159 \\
p>0.11\end{array}$ & $\begin{array}{l}0.091 \\
p>0.36\end{array}$ & $\begin{array}{l}0.220^{*} \\
p<0.03\end{array}$ & $\begin{array}{l}0.241^{*} \\
p<0.01\end{array}$ & $\begin{array}{l}0.162 \\
p>0.10\end{array}$ \\
\hline $\begin{array}{l}\text { Job } \\
\text { opportunity }\end{array}$ & $\begin{array}{l}0.441^{* *} \\
p<0.00\end{array}$ & $\begin{array}{l}0.317^{* *} \\
p<0.01\end{array}$ & $\begin{array}{l}0.274^{* *} \\
p<0.00\end{array}$ & $\begin{array}{l}0.285^{* *} \\
p<0.02\end{array}$ & $\begin{array}{l}0.329^{* *} \\
p<0.00\end{array}$ & $\begin{array}{l}0.319^{* *} \\
p<0.00\end{array}$ & $\begin{array}{l}0.211^{*} \\
p<0.03\end{array}$ & $\begin{array}{l}0.344^{* *} \\
p<0.00\end{array}$ & $\begin{array}{l}0.219^{*} \\
p<0.03\end{array}$ \\
\hline
\end{tabular}

The predictive values evidenced from perceived correlation coefficients (Table 2). Commitment in the workplace correlates with eight of the nine sub-components of the job satisfaction which are as follows: Income $(r=0.43)$, supervision $(r=0.35)$, benefits $(r=0.23)$, rewards $(r=0.29)$, working procedures $(r=0.32)$, associates $(r=0.28)$, the nature of the work $(r=0.30)$ and communication $(r=0.29)$. The only statistically insignificant correlation was confirmed between predictor variables "advancement" and the criterion variable commitment at work $(r=0.17)$.

The determination of whether the information provided by the model which includes all nine sub-components of the job satisfaction is valid or not for the prediction possibility of work it is realized through analysis of variances. The coefficient $F=3.26 p<0.00$ suggests that among the information that ensures the model, which includes nine subcomponents, is valid because between the explained part and the unexplained one, from overall variance of the multiple regression, exists the difference which is statistically important.

Determination of the predictive value of sub-components, of the job satisfaction it is realized through step-wise procedure, respectively through successive inclusion of the special predictor in the regressive analysis (Table 3). 


\begin{tabular}{|c|c|c|c|c|c|c|}
\hline & predictor & $R^{2}$ parcial & B & p & $t$ & p \\
\hline \multicolumn{7}{|c|}{ The model of the variable criteria: Job opportunity } \\
\hline \multirow{9}{*}{$R^{2}=0.238 p<.001$} & Income & $R^{2}=0.194 ; p<.001$ & 0.441 & 0.00 & 4.96 & 0.00 \\
\hline & Upgrading & $R^{2}=0.101 ; p<.001$ & 0.317 & 0.00 & 3,38 & 0.00 \\
\hline & Supervision & $R^{2}=0.075 ; p<.001$ & 0.274 & 0.00 & 2.88 & 0.00 \\
\hline & Benefits & $R^{2}=0.081 ; p<.001$ & 0.285 & 0.02 & 2.99 & 0.00 \\
\hline & Rewards & $R^{2}=0.108 ; p<.001$ & 0.329 & 0.00 & 3.52 & 0.00 \\
\hline & Working Procedures & $R^{2}=0.102 ; p<.001$ & 0.319 & 0.00 & 3.40 & 0.00 \\
\hline & Associates & $R^{2}=0.044 ; p<.003$ & 0.211 & 0.00 & 2.18 & 0.03 \\
\hline & Nature of Work & $R^{2}=0.112 ; 0<.001$ & 0.334 & 0.00 & 3.58 & 0.00 \\
\hline & Communication & $R^{2}=0.048 ; p<.003$ & 0.219 & 0.00 & 2.27 & 0.03 \\
\hline \multicolumn{7}{|c|}{ The model of the variable criteria: Job opportunity } \\
\hline \multirow{5}{*}{$R^{2}=0.215 p<.001$} & Income & $R^{2}=0.194 ; p<.001$ & 0.441 & 0.00 & 4.96 & 0.00 \\
\hline & Nature of Work & $R^{2}=0.112 ; p<.001$ & 0.334 & 0.00 & 3.58 & 0.00 \\
\hline & Rewards & $R^{2}=0.108 ; p<.001$ & 0.329 & 0.00 & 3.52 & 0.00 \\
\hline & Working procedures & $R^{2}=0.102 ; p<.001$ & 0.319 & 0.00 & 3.40 & 0.00 \\
\hline & Upgrading & $R^{2}=0.101 ; p>.001$ & 0.317 & 0.00 & 3.38 & 0.00 \\
\hline
\end{tabular}

The results presented in Table 3 verify that the model in which are included structural components of the job satisfaction explains the $23.8 \%$ of the variance the criterion variable opportunity to work. With that the contribution of some subcomponents of the job satisfaction is very little it is passed on research in the regressive procedure model which will also include a smaller number of the predictors without compromising his predictive value. Through the successive inclusion in the model of the predictors at the same time increases the value of regressive coefficients. But the biggest contribution ensures sub-components model which includes "income" (6.8\%), followed by sub-component "nature of work" (3.9\%), rewards (3.8\%), procedure employment (3.6\%) and sub-component "progress" (3.5\%) that together explain the $21.5 \%$ of the possibility to work.

In Table 3 are provided the partial regressive standardized coefficients (beta column). From the height of Partial coefficients we can conclude that statistically significant contribution of the criterion variable predicting job opportunity ensure the predictors: a) emphasized satisfaction which derives from income ( $B=0.19 ; p<0.01)$, b) satisfaction emphasized which derives from the nature of the work ( $\beta=0.33 ; p<0.01), c)$ the rewards $(B=0.33 ; p<0.01$ ), $d$ ) the working procedure $(B=0.32 ; p<0.01)$ and $d)$ the satisfaction which derives from advancing commitment at work $(B=$ $0.32 ; p<0.01$ ). In the context of other predictors (benefits, rewards, associates, supervision and communication), also regarding their partial contribution is statistically significant, nevertheless the same will not be included in the predictive model because of small contribution they prediction for yield the criterion variable.

The predictive values evidenced from perceived correlation coefficients (Table 2). Opportunity to work correlates with all nine sub-components of the job satisfaction which are as follows: Income $(r=0.44)$, promotion $(r=0.32)$, supervision $(r=0.27)$, benefits $(r=0.29)$, rewards $(r=0.33)$, work procedures $(r=0.32)$, associates $(r=0.21)$, the nature of the work $(r=0.34)$ and communication $(r=0.21)$.

To test whether sub-components of the job satisfaction can validly predict, statistically, the level of professional involvement, standard linear regression was developed.

Table 4. Multiple regression coefficients when as predictive variable are presented sub-components of the job satisfaction.

\begin{tabular}{|l|r|r|r|r|r|r|}
\hline Model & $R$ & $R$ Square & $\begin{array}{l}\text { Adjusted } \\
\text { R Square }\end{array}$ & $\begin{array}{l}\text { Std. Error of } \\
\text { the Estimate }\end{array}$ & $F$ & Sig. \\
\hline 1 &, $306^{2}$ &, 093 &, 007 & 5,708 & 1.076 & $.388^{2}$ \\
\hline
\end{tabular}

a. Predictors: (Constant), income, upgrading, supervision, benefits, reward working procedures, associates, nature of work, communication

From the results shown in Table 4 could be understood that the model which in itself integrates the structural components of the working job satisfaction in predicting the job involvement is statistically insignificant. On the other hand, the value of $F=1.08$ p> 0.05 suggests that determination coefficient is statistically insignificant; respectively information which ensures the model which in itself brings job satisfaction is small and insignificant.

\subsection{Predictive value of the set variables in the sub-samples of the subjects with different duration in the current position}

To test whether the relevant variables, which refer to the policy of human resources management in the organization, can 
validly predict, statistically, commitment in the workplace, job involvement and the possibility of the employees to work in the bank, was developed a linear regression standard.

Table 5. Multiple regression coefficients when as predictive variable are presented relevant variables

\begin{tabular}{|l|r|r|r|r|r|r|}
\hline $\begin{array}{c}\text { Model } \\
6\end{array}$ & $R$ & R Square & $\begin{array}{r}\text { Adjusted } \\
\text { R Square }\end{array}$ & $\begin{array}{r}\text { Std. Error of } \\
\text { the Estimate }\end{array}$ & $F$ & Sig. \\
\hline 1 &, $190^{2}$ &, 036 &,- 056 & 12,10302 & 0.392 & $.936^{2}$ \\
\hline
\end{tabular}
a. Predictors: (Constant the type of awards, the number of prizes,
upgrading, commitment at work duration, the amount of salary the
position commitment at work, the duration of the current position, the
number of upgrades
b. Criterion variable: Commitment in the Workplace

Results of the regression (Table 5) showed that the model of inclusion of relevant variables: the type of awards, the number of prizes, Upgrading, commitment at work duration, the amount of salary the position commitment at work, the duration of the current position, the number of upgrades, all together explain the $3.6 \%$ of the variance of commitment in the workplace of employees in the bank $(R=.190)$. The value of $F=0,39 ; p>0.01$ implies the conclusion that determination coefficient is statistically insignificant; respectively information which ensures the model which in itself brings relevant variable is small and insignificant.

Results of the regression (Table 5) confirm that the model which includes the set of relevant variables: the type of rewards, the number of rewards, upgrading, duration at work, the amount of salary, the position at work, the duration of the current position, the number of increased duties in office, all together explain the $9.4 \%$ of the variance of job involvement of the working employees in the bank $(R=.306)$. The value of $F=1.08, p>0.01$ implicates the conclusion that determination coefficient is statistically insignificant; respectively information which ensures the model which in itself brings relevant variable is small and insignificant.

Results of the regression (Table 5) claim that the model which includes the set of relevant variables: the type of rewards, the number of rewards, upgrading, at work duration at work, the amount of salary, the position at work, the duration of the current position, the number of increased duties in office, all together explain the $2.5 \%$ of the variance of job involvement of the working employees in the bank $(R=.159)$. The value of $F=0.27, p>0.01$ implicates the conclusion that determination coefficient is statistically insignificant; respectively information which ensures the model which in itself brings relevant variable is small and insignificant.

Non-standardized and standardized values as well as statistical validity for each variable included in the regression indicate that the relevant variables (type of rewards, the number of rewards, Upgrading, at work duration at work, the amount of salary, the position at work, the duration of the current position and the number of upgrades) were not statistically valid. The concerned variables may be removed from predicative model for commitment in the workplace, job involvement and job opportunity.

\section{Discussion}

The aim of the research was the verification of the predictive value of satisfaction in to work and relevant factors. Nevertheless the important aim of the research was to determine the relevance of Devizes that "employees who are satisfied with the work at the same time are also productive worker". In other words, Does linear relationship exists between job satisfaction and commitment in the workplace; respectively employees who are satisfied with a job are at the same time in the same measure also professionally engaged as well as productive?

Statistical analysis, such as correlative as well as the regressive it confirmed that exists a positive linear relationship between job satisfaction and commitment in the workplace. However, the link concerned is not considerably in mutual/deterministic correlation. The satisfaction and the commitment in the workplace arguably should not be directly in relation. Between the satisfaction and commitment in the workplace relation exists because of both working variables are closely correlated with the third factor - the possibility to work. This relation is further strengthened with the inclusion of other factors, as inclusion in the work.

Predictors' recognition of commitment in the workplace has a multiple pragmatic character. Workers who are not satisfied with the work very quickly can experience as "burn out". Moreover, this situation psychologists deem it as psychological "burnout syndrome". Therefore, treatment and scientific knowledge of predictors of commitment in the workplace should be considered more than a functional element which is available to "human resources management - 
HRM"'. Predictors of satisfaction, primarily should be seen in the light of the function "the preventive", in which HRM' will provide knowledge not only on the performance of employees for being not / or productive but also general information on mental status. In this way, it can be a preventive effect on the progress and regress of the consequences deriving from "burn out". If the employee is not satisfied with the work, this exercise will be reflected not only in its overall performance in work but above all of its total personal status. Qualitative analysis of the results of relevant research confirms similar results with the results of our research (Spector, 1985)

The research stated that "the work in banks" should not be perceived only through the "economic" function - eight working hours to achieve productivity". HRM in its policy management should not bypass the other functions of "working" first of all those "psychosocial". Gained correlations between structural components in work satisfaction and commitment in the work suggest the last one correlates with the variables referring to the psychological character of the work: working procedures and supervision. If we analyze their substantial side we will see that they include human character, because the working procedure also determines supervision in and at the same time manages HRM Office.

Also, the research stated that job satisfaction and commitment in the workplace should be treated in the light of a spectrum of attitudes that the employee shall refer its work. Employees develop the more positive and more reflective attitude about some aspects of the work: (e.g. the extrinsic Incentives, natural and work procedures) others feel them as less important (e.g. benefit payments from work) and finally to some extrinsic indifference (e.g. upgrade).

The predictive model emerging from this research in itself brings implicit persuasion that the main motto of the employees in the bank's is their own "output" from work, respectively "income" as compensated material from the work realized. As a result of this, the bank employee as much as he gains from the "output" (income) that at most appreciates the greater will be the satisfaction and commitment in the workplace. In favor of affirmation goes predictive data analysis that is developed according to which, the relevant variables (upgrade, and the kind of reward) are not correlated with the criterion variables (commitment in the workplace, job involvement and the job opportunity) to which their contribution to the prediction of criterion variables we consider as unimportant. In other words, the source of job involvement the employees in the bank absorbs at the same time from two sources such as: from the extrinsic Incentives of (material revenues) and by characteristics that are related to the work (working procedures, the nature of work and supervision).

The following suggestion for HRM towards the advancement of job involvement the employee is mono-conceptual dissemination of the perception of work, respectively "the work" must be perceived as a conglomerate of elements. Employees mostly in banks look at "work" through the prism of "existential" by making efforts in order to press the importance of feelings that derive from the work done.

Depending on the height of the gained correlations between structural components of job satisfaction and job involvement of the employees can shape motivational diagram which for HRM can serve as a strategy for motivating employees in the company. To have more consistent commitment it is needed that in the system of professional motivation to primarily include material compensation through "income", later on the functional elements that are related to the work (nature of work and working procedures) and finally to intervene with the a proactive approach in social relations (communication and associates). By coordinating the motivators can be concluded that the motivation for commitment in the workplace of the Employees in the bank has a proactive character of individualist orientation. This orientation in the multiplicative context, the issues such as commitment and job satisfaction, is conceptualizing them as the amount of job satisfaction and commitment with the specific elements of work, as well as with their importance.

General attitude which could be examined by the results of this research is that the commitment in the workplace is determined by the characteristics of the work: (nature of work, work procedures) and by the subject itself (benefits) and the social determinants (associates, communication, and supervision). Also, the results allow the drawing an explicit generalization report on structural components in work satisfaction and commitment, and job opportunity, respectively the components are statistically predict importance of commitment in the workplace and job opportunity but not the professional involvement. It remains that in the new research, which as a point of reference should take the results of this research, for exploring the inclusion predictors.

For the end, it is needed to have a proactive approach to employees in order to efficient and effective function of company. This means that by holding or displaying of equivalence between individual and organizational goals in order to maximize the maxim outcome of this research on "the commitment in the workplace, the job satisfaction and the job opportunity efficiently leads to a greater organizational effectiveness."

\section{References}

Bashaw, R.E., \& Grant, E.S. (1994). Exploring the distinctive nature of work commitments: Their relationships with personal characteristics, job performance, and propensity to leave. Journal of Personal Selling \& Sales Management, 14, 1-16. 
Carlson, J.R., Anson, R.H., Thomas, G. (2003): Correctional Officers Burnout and Stress: Does Gender Metter? The Prison Joumal, 83 (3), 277-288

Grinberg J., Baron R. (1998). Ponašanje ljudi u organizacijama, Beograd: Želnid.

Herzberg, F. (1968). One more time: How do you motivate employees? Harvard Business Review, (Jan-Feb) 53-62.

Herzberg, F., Mausner, B., Patterson, R. O., \& Capwell, D. F. (1957). Job attitude: Review of research and opinion. Pittsburgh: Psychological Services of Pittsburgh.

Holmes Norton, E. (2003). Women in prison: Sexual Misconduct by Conectional Staff, United States General Accounting Office Report, http://www.gao.gov.

Lambert, E.G., Paoline, E.A., Hogan, N.L., Baker, D.N. (2007): Gender Similarities and Differences in Correctional Staff Work Attitudes and Perception of the Work Environment. Westem Criminology Review, 8 ( I ), 16-3 I.

Martin Hasselhorn H., Work Ability - Concept and Assessment (2008). Enterprise for Health Management Conference' in London conference guide, 1.

Spector, P. E. (1985). Measurement of human Service Staff Satisfaction: Development of the Job Satisfaction Survey. American Journal of Community Psychology, 13, 693-713.

Spector, P. E. (1997). Job Satisfaction: Application, Assessment, Causes, and Consequences. California: Sage Publications.

Wright, Th. A. (2006). The emergence of job satisfaction in organizational behavior, A historical overview of the dawn of job attitude research. Journal of Management History, 12, 262-277. 